\title{
Gramática Cognitiva e eventos de uso: o conectivo causal "resultado"
}

Lilian Ferrari $^{1}$

\begin{abstract}
Resumo: Este trabalho adota a perspectiva teórica da Gramática Cognitiva (LANGACKER, 1987, 1991), com o objetivo de descrever o modo pelo qual unidades linguísticas são abstraídas de eventos de uso que, por sua vez, são caracterizados como instâncias reais de uso linguístico. Na esteira de propostas anteriores que enfocam conectivos causais do inglês - "therefore" (LANGACKER, 2001) - e do português brasileiro - "por isso" e "portanto" (FERRARI \& ANDRADE, 2015), apresenta-se uma proposta de análise do conectivo causal "resultado" do português brasileiro. A partir de dados de língua escrita, retirados do Corpus do Português (http://www.corpusdoportugues.org), a análise desenvolve o argumento de que a unidade linguística "resultado" reflete a esquematização da relação entre as proposições P1 (causa) e P2 (consequência), e da sinalização implícita da perspectiva do falante com relação ao evento descrito em P2. Em particular, o conectivo sinaliza que, sob o ponto de vista do falante, P2 é indesejável e/ou contrário às expectativas.
\end{abstract}

Palavras-chave: Gramática Cognitiva, unidade linguística, evento de uso, conectivo causal

\section{Introdução}

As abordagens funcionais e cognitivas partem da premissa comum de que a linguagem humana tem suas bases no discurso. No que se refere à Linguística Cognitiva (LC), embora a análise de porções discursivas mais amplas se trate de fenômeno relativamente recente (SANDERS e SPOOREN, 2007; OAKLEY e HOUGAARD, 2008; MODER, 2013), a relação estreita entre sequências discursivas e unidades linguísticas foi reconhecida pioneiramente por Ronald Langacker (2001, p. 143). Ao lançar as bases da abordagem teórica rotulada inicialmente como Space Grammar ("Gramática do Espaço”) e, posteriormente, consolidada com a denominação Cognitive Grammar ("Gramática Cognitiva"), o autor cunhou o termo usage-based model ("modelo baseado no uso"), associando-o à proposta de que a língua é instrumento de organização, processamento e transmissão de informação, e não sistema autônomo.

A partir dessas considerações, este trabalho enfoca a integração do uso à análise linguística na Gramática Cognitiva. Dentro dessa perspectiva, a noção basilar de "evento de

\footnotetext{
${ }^{1}$ Professora Titular do Departamento de Linguística da Universidade Federal do Rio de Janeiro (UFRJ). Coordenadora do Laboratório de Pesquisas em Linguística Cognitiva (LINC-UFRJ). Pesquisadora do CNPq.
} 


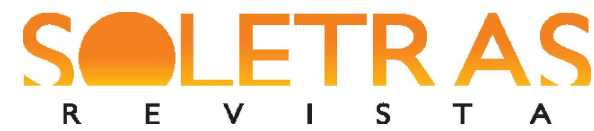

N.37 - 2019.1 - LILIAN FERRARI

uso" é apresentada, sendo detalhada em termos de seus componentes básicos e associada às unidades linguísticas. $\mathrm{Na}$ esteira desta perspectiva teórica, o presente trabalho enfoca o conectivo causal "resultado" do português brasileiro, com o objetivo de caracterizar os componentes dos eventos de uso que são esquematizados nessa unidade linguística.

O trabalho está organizado em quatro seções principais. A seção "Gramática Cognitiva e eventos de uso" traça um panorama dos estudos que prenunciam a inclusão do uso linguístico nas agendas funcionalista e sociolinguística, detalhando, mais especificamente, a caracterização de eventos de uso na Gramática Cognitiva. A seção "Unidades linguísticas e eventos de uso" discute o modo pelo qual unidades linguísticas, tais como itens lexicais, pronomes pessoais, conectivos, etc., são abstraídas de eventos de uso. A seção "Conectivos causais e eventos de uso" retoma a análise de Langacker (2001) para o conectivo "therefore" em inglês, e a proposta de Ferrari \& Andrade (2015) para os conectivos "por isso" e “portanto" em português. Na seção "Metodologia”, são apresentados aspectos metodológicos referentes ao banco de dados, objetivos e hipóteses da pesquisa. Por fim, a seção "Análise do conectivo resultado" apresenta uma proposta de análise do uso de "resultado" como conectivo causal no português brasileiro. $\mathrm{O}$ argumento desenvolvido no artigo é o de que esse uso representa uma esquematização do evento de fala, que inclui implicitamente o Ground e a perspectiva do falante como parte do significado. Em particular, essa esquematização envolve uma avaliação, por parte do falante, da proposição que representa a consequência (P2) como indesejável e/ou contrária às expectativas.

\section{Gramática Cognitiva e eventos de uso}

A preocupação com o uso linguístico real pode ser observada há décadas, a partir de diferentes contribuições teóricas, entre as quais se destacam: (i) estudos do uso da gramática no discurso, em que se preconiza que o "discurso molda a gramática" (DUBOIS, 1985; GIVÓN, 1979; HOPPER \& THOMPSON, 1980), (ii) investigações sociolinguísticas que priorizam a fala espontânea para a análise da variação linguística (LABOV, 1972; Sankoff \& Brown 1976); (iii) pesquisas funcionalistas sobre gramaticalização, que concebem a forma gramatical e o significado como emergentes a partir de instâncias repetidas de uso linguístico (BYBEE, 2003a, 2003b; HOPPER \& TRAUGOTT, 2003). 


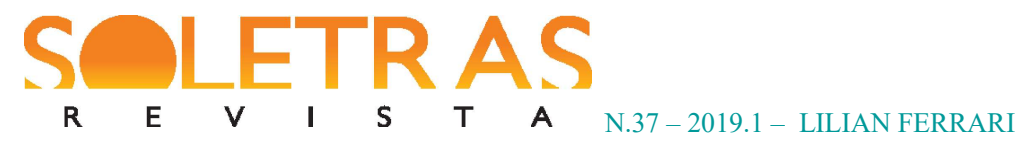

Atualmente, os modelos baseados no uso representam uma confluência de perspectivas de pesquisa que consideram o efeito do uso na representação linguística. A premissa compartilhada por essas abordagens é a de que a gramática é um sistema dinâmico, de categorias emergentes e sempre mutáveis, em função da influência de processos cognitivos gerais envolvidos no uso linguístico (HOPPER, 1987; BYBEE, 2010; DIESSEL, 2015).

Vale notar, entretanto, tal como reconhecido por Barlow \& Kemmer (2000), que o termo "usage-based" foi pioneiramente cunhado por Langacker (1987), como evidencia o excerto a seguir:

Os gramáticos gerativistas sempre operaram com uma concepção arquetípica de língua, como um sistema geral de regras e, portanto, não acomodaram fenômenos irregulares e idiossincráticos...A Gramática Cognitiva, em contraste, é uma teoria baseada no uso... Ao invés de considerar estruturas idiossincráticas como um problema, a Gramática Cognitiva concebe estruturas particulares como matrizes a partir das quais estruturas gerais são abstraídas. (LANGACKER, 1987: 46)

Em clara oposição ao modelo gerativo, portanto, o uso ocupa o cerne da Gramática Cognitiva (LANGACKER 1987, 1991), de modo que os eventos de uso são detalhadamente descritos no modelo. Nos termos da Gramática Cognitiva, todas as unidades linguísticas são abstraídas de eventos de uso que, por sua vez, são caracterizados como instâncias reais de uso linguístico.

Essas instâncias envolvem necessariamente dois polos: conceptualização e vocalização. A conceptualização envolvida em um evento de uso inclui a apreensão dos interlocutores das circunstâncias interacionais (Ground), e do discurso no qual estão engajados (Espaço Discursivo Corrente). O Ground (G) inclui o falante, o ouvinte, interação entre ambos e as circunstâncias imediatas do evento de fala (em particular, tempo e local); já o Espaço Discursivo Corrente (EDC) é o espaço mental que reúne os elementos e relações compartilhados por falante e ouvinte como base para a comunicação em um dado momento no fluxo discursivo.

Na comunicação bem-sucedida, falante e ouvinte dirigem e focalizam a atenção para a mesma entidade, engajando-se em uma percepção coordenada de um determinado aspecto do mundo ('coordinated viewing'). Tendo em vista que há limitações quanto ao que pode ser 


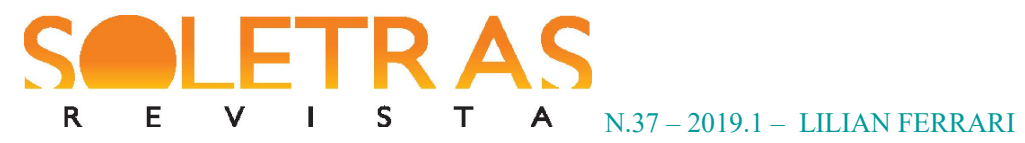

retido no campo visual (ou conceptual) a cada vez, é como se, metaforicamente, o mundo fosse percebido através de uma janela de visualização ('viewing frame'). Sendo assim, o escopo imediato da conceptualização, a cada vez, é limitado ao que aparece nessa "janela", e o foco de atenção (o que a expressão designa) fica incluído nesse escopo. A Figura 1 detalha, de forma esquemática, os elementos envolvidos em um evento de uso linguístico:

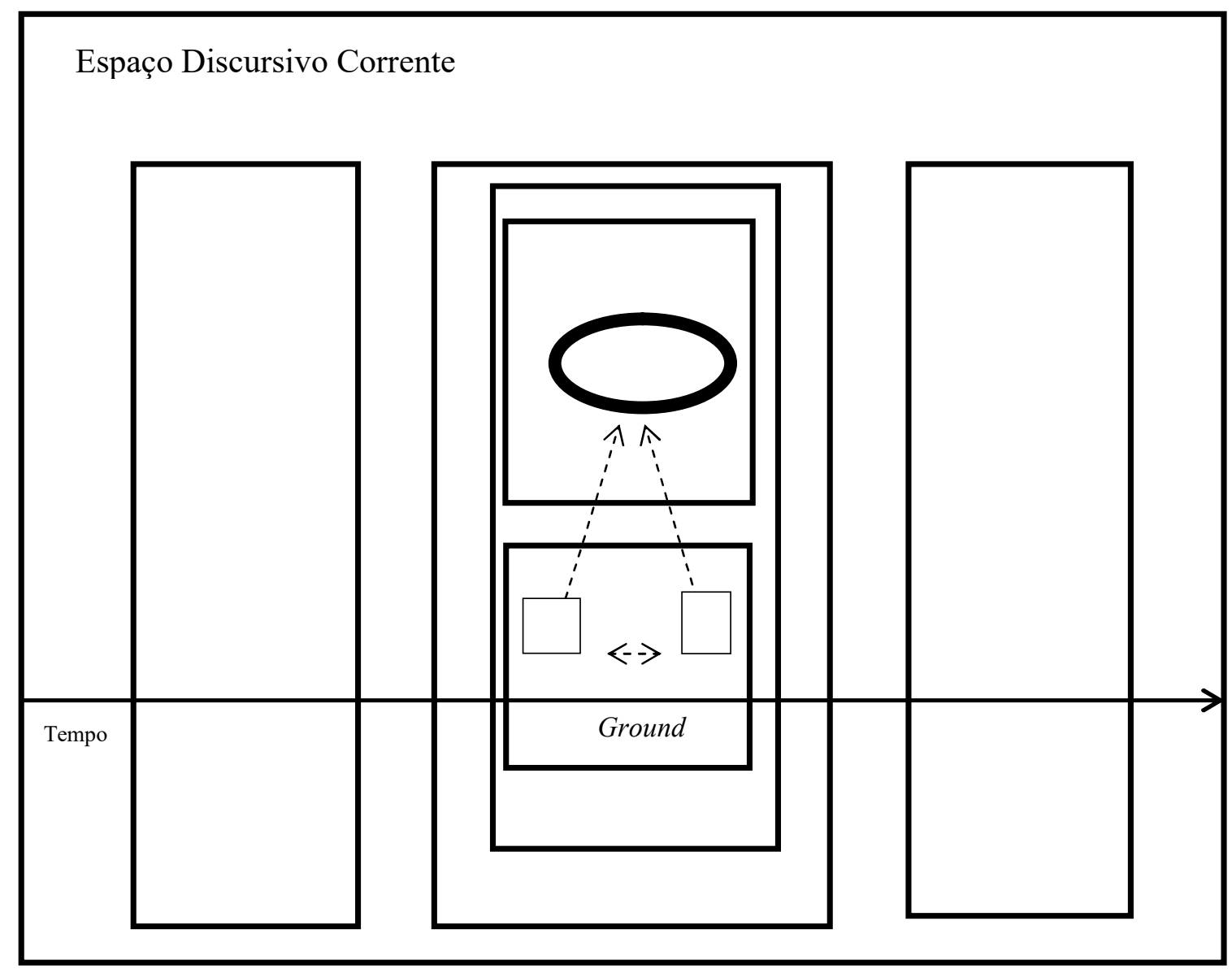

Figura 1 - Evento de uso (Fonte: LANGACKER, 2001, p. 145)

A Figura 1 evidencia que um evento de uso tem lugar em um contexto imediato de fala, que geralmente inclui circunstâncias físicas, mentais, sociais e culturais. O Ground fica no centro do contexto de fala, tendo como destaque o engajamento de falante e ouvinte na visualização coordenada de uma faceta do mundo.

Além do contexto de fala, o EDC inclui o conhecimento presumidamente compartilhado e razoavelmente acessível a falante e ouvinte. Inclui, ainda, a apreensão do 


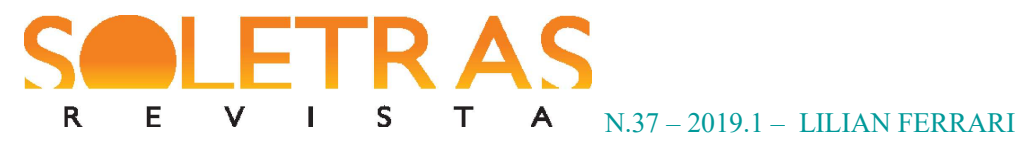

falante e do ouvinte do discurso em andamento - uma série de eventos de uso precedentes, assim como eventos subsequentes que poderiam ser antecipados. Qualquer faceta desses eventos pode servir de base ou mesmo ser retomada no evento de uso corrente.

Como mencionado anteriormente, a "janela de visualização" (viewing frame) tem natureza bipolar, incluindo tanto a conceptualização quanto a vocalização. Vejamos:

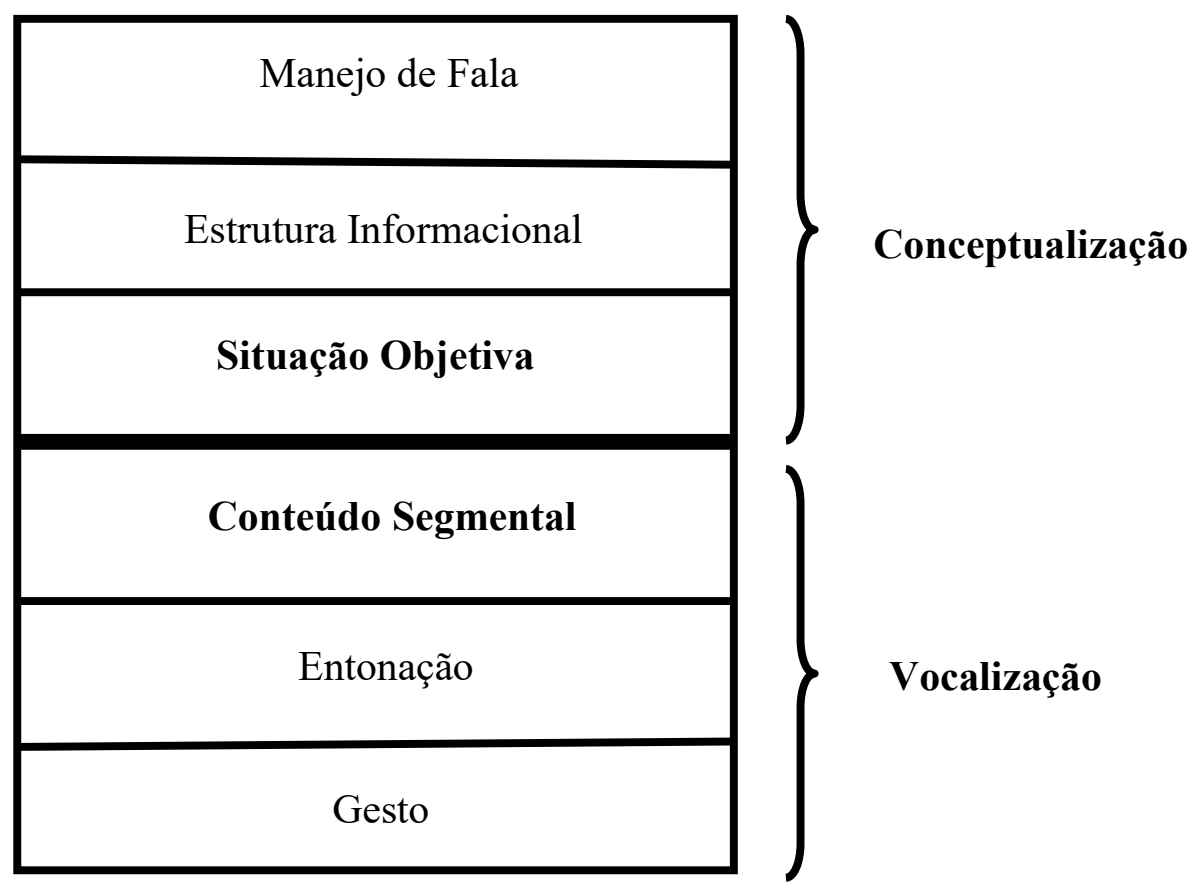

Figura 2 - Janela de Visualização (Viewing Frame)

$\mathrm{Na}$ janela de visualização, cada um dos polos é constituído por múltiplos canais, coordenados de formas complexas. Os canais que integram o polo de conceptualização incluem a situação objetiva, a estrutura informacional (ex. ênfase, tópico discursivo, status dado/novo dos referentes) e o manejo da fala (ex. tomada e manutenção de turno). Os canais de vocalização, por sua vez, incluem o conteúdo segmental, a entonação e os gestos.

Langacker (2001, p.146) sugere, ainda, que embora todos os canais estejam em foco na janela de visualização, a situação objetiva, no polo de conceptualização, e o conteúdo segmental, no polo de vocalização, são geralmente mais centrais do que outros fatores do mesmo polo, por serem comparativamente mais saliente. 


\section{Unidades linguísticas e eventos de uso}

Ao considerar que todas as unidades linguísticas são abstraídas de eventos de uso, Langacker (2001) lança as bases para a articulação entre expressões linguísticas e contexto discursivo. $\mathrm{O}$ autor ressalta que as unidades linguísticas devem ser concebidas como padrões esquematizados de ação imanentes nos eventos de uso, e não como entidades distintas. Assim, as unidades emergem pelo reforço e "entrincheiramento" progressivo de elementos em comum, que são recorrentes em um número suficiente de eventos. Essas unidades são, portanto, rotinas cognitivas multifacetadas que podem ser ativadas no momento oportuno (como a habilidade de assinar o próprio nome). Os padrões emergentes incluem desde itens lexicais típicos (ex. árvore) até elementos pragmaticamente marcados, tais como preenchedores de lacuna na conversação (ex. hum), pronomes pessoais (ex.. $2^{\mathrm{a}}$ p.s. 'tu'), demonstrativos acompanhados de gestos (ex.. aquele $[\rightarrow]$ lá) e conectivos (ex. por isso).

Tanto os itens lexicais típicos quanto outros tipos de unidade linguística compartilham a generalização de que constituem uma expressão que está sendo empregada por um falante, em um determinado contexto de fala, como parte de um discurso. Se essa generalização é comum aos eventos de uso, todas as unidades linguísticas são abstraídas, minimamente, de um framing esquemático completo, tal como representado na Figura 1, mesmo que apenas alguns setores sejam especificados em detalhe. Por exemplo, itens lexicais como "árvore" são mais específicos com relação a elementos da janela de visualização (entidade objetiva e conteúdo segmental), mas altamente esquemáticos em relação a outros setores representados no diagrama (unidades precedentes e subsequentes, Ground, etc.). Há, entretanto, algumas possibilidades de variação:

(i) Preenchedores de lacunas - perfilamento de elementos da janela de visualização: o conteúdo segmental (ex: hum), no polo de vocalização, e o manejo da fala (iniciar o turno), no polo de conceptualização. O Ground, assim como unidades precedentes e subsequentes, permanece esquemático.

(ii) Pronome pessoal de $2^{\mathrm{a}}$ pessoa do singular - perfilamento do conteúdo segmental (ex. tu), no polo de vocalização, e do interlocutor objetivo, no espaço de conceptualização. O Ground é objetificado.

(iii) Conectivos - perfilamento do conteúdo segmental (ex. por isso), no polo de vocalização, e da relação causal entre eventos objetivos $(\mathrm{P} 1 \rightarrow \mathrm{P} 2)$, no polo de 
conceptualização. É preciso, ainda, identificar P1 com uma proposição P expressa em um evento de uso anterior no fluxo discursivo.

Levando em conta unidades linguísticas como as exemplificadas acima, Langacker (2001) propõe que configurações discursivas recorrentes coalescem como unidades incorporadas ao sistema linguístico, constituindo padrões esquematizados de ação controlados pelos falantes. Em princípio, qualquer unidade linguística contém todos os setores representados na Figura 1, mas as unidades variam quanto ao grau de esquematicidade/especificidade de muitos desses setores.

\section{Conectivos causais e eventos de uso}

No que se refere aos conectivos causais, a esquematização é ilustrada por Langacker, a partir de um exemplo em que a relação causal é sinalizada por therefore:

(1) He's very rich and powerful. Therefore I like him.

"Ele é muito rico e poderoso. Por isso eu gosto dele."

A descrição completa do conectivo é assim representada pelo autor:

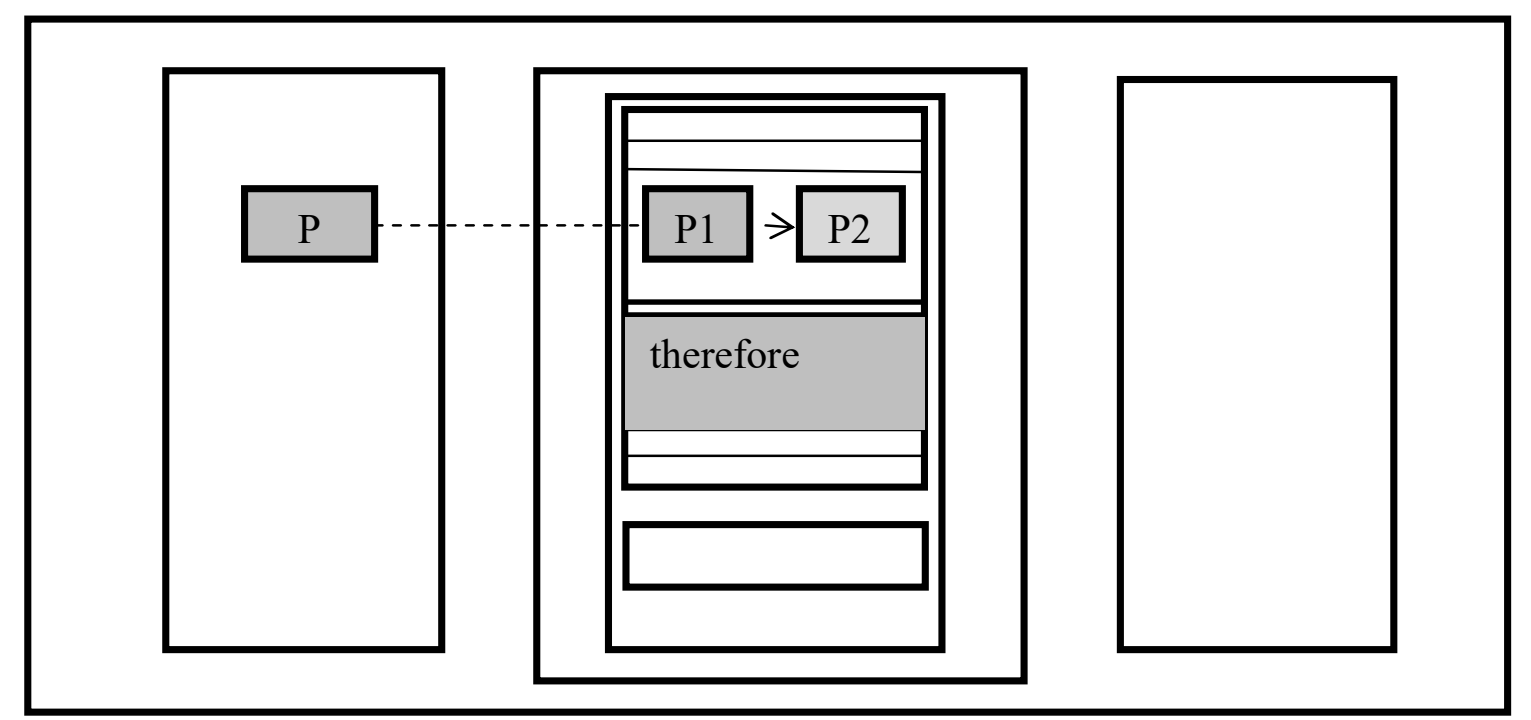

Figura 3 - Descrição completa do item lexical "therefore" (Fonte: LANGACKER, 200, p.149). 


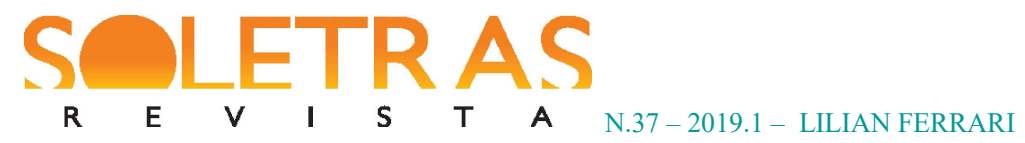

Como se vê na Figura 3, o conectivo "therefore" ("por isso") introduz e perfila ${ }^{2}$ uma relação em que a proposição P2 é subsequente à proposição P1. Além disso, P1 é identificada com a proposição expressa no evento de uso prévio, ocorrido anteriormente no fluxo discursivo. Vale destacar, ainda, que quando associado a elementos específicos, "therefore" ("por isso") cria expectativas discursivas engendradas por esses elementos; no caso, a expectativa de que $\mathrm{P} 2$ ocorra.

Com relação ao português brasileiro, Ferrari \& Andrade (2015) analisaram contextos reais de uso dos conectivos causais "portanto" e "por isso", a partir do modelo dos espaços mentais (SANDERS, SANDERS \& SWEETSER, 2009; FERRARI \& SWEETSER, 2012). As autoras argumentam que o conectivo "portanto" perfila uma relação causal entre duas proposições, além de sinalizar uma conclusão do falante. Vejamos o seguinte exemplo apresentado pelas autoras ${ }^{3}$ :

(2) Um inglês que aqui esteve em 1893 deixou registrado que o maior elogio que se podia fazer a uma dama era observar que ela "estava a cada dia mais gorda”. (...). É possivel, portanto, que a estética das mulheres fortes seja apenas uma evolução histórica do gosto nacional por mulheres curvilíneas, que predomina há 500 anos.

Em (2), dada a proposição P ("o maior elogio que se podia fazer a uma dama ora observar que ela estava a cada dia mais gorda"), o falante estabelece a conclusão Q ("é possível que a estética das mulheres fortes seja apenas uma evolução histórica do gosto nacional por mulheres curvilineas").

As autoras apontam, ainda, que o conectivo por isso apresenta a relação causal como algo independente de processos epistêmicos:

(3) O Brasil não tem um satélite meteorológico e, por isso, usa dados enviados pelos Estados Unidos. O satélite americano envia imagens ao Brasil a cada 30 minutos, quando o ideal seria a cada 15 minutos.

\footnotetext{
${ }^{2} \mathrm{Na}$ Gramática Cognitiva, a noção de 'perfil' (profile) diz respeito à subestrutura particular de uma base conceptual, para a qual se dirige o foco de atenção. Na Figura 3, o caráter elaborado (i.e, específico) dos elementos do diagrama é indicado pela cor cinza. A mesma notação é adotada nos demais diagramas apresentados no texto.

${ }^{3}$ Os dados foram retirados do Corpus LINC-modalidade escrita, que reúne textos jornalísticos publicados em treze edições da Revista Época (n. 610 a 615; n. 620-626), do ano 2010.
} 


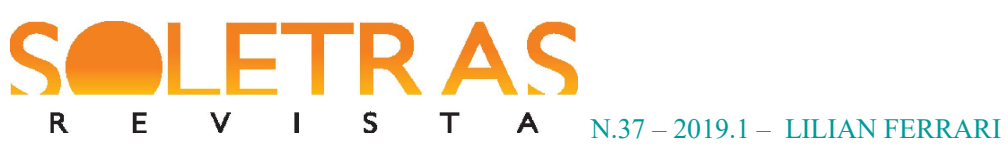

O exemplo (3) envolve uma relação causal em que a proposição P ("O Brasil não tem um satélite meteorológico") é apresentada como causa da ação volitiva descrita em Q ("O Brasil usa dados enviados pelos Estados Unidos" $)^{4}$

Embora Ferrari \& Andrade (2015) tenham adotado a teoria dos espaços mentais como referencial teórico, os resultados são compatíveis com a proposta langackeriana. Assim, podese considerar que as propostas apresentadas nesta seção reúnem generalizações sobre as relações entre diferentes tipos de conectivos causais e eventos de uso. No caso do conectivo "therefore" ("por isso"), a representação estabelecida na Figura 3 inclui esquematicamente o Ground, mas não especifica a participação de elementos do Ground no significado convencional. Esse também é o caso do conectivo "por isso" em português, que também não envolve referência ao espaço Base (correlato teórico do Ground, no modelo dos espaços mentais).

Há, entretanto, conectivos que atribuem papel menos esquemático ao Ground. Esse é o caso do conectivo "portanto", que sinaliza uma conclusão implícita do falante. Esse também parece ser o caso do conectivo causal "resultado", que não apenas sinaliza uma conclusão, mas indica uma avaliação do falante em relação a essa conclusão. Essa proposta será apresentada na seção de análise.

\section{Metodologia}

Para investigar as relações entre unidades linguísticas e eventos de uso, a pesquisa selecionou, como objeto de estudo, a unidade linguística "resultado". Embora o item seja prototipicamente um nome (ex: “O resultado ficou abaixo das expectativas"), verificam-se usos no português brasileiro em que "resultado" funciona como conectivo causal, como ilustra o exemplo a seguir:

(4) Tenho hormônios baixos, e o útero invertido. Resultado: não consegui engravidar.

\footnotetext{
${ }^{4}$ Embora 'Brasil' não seja um sujeito volitivo, os usos aqui são metonímicos; assim, 'Brasil' faz referência a ‘indivíduos responsáveis pelas decisões tomadas pelo governo brasileiro' - esses, sim, agentes volitivos. 


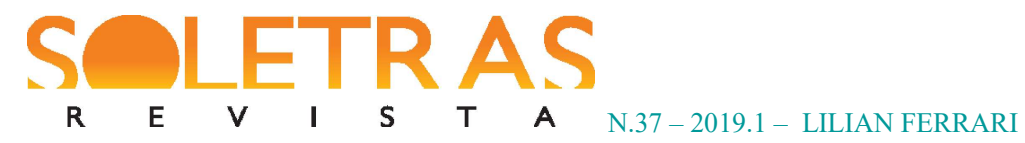

Os dados foram retirados do Corpus do Português (http://www.corpusdoportugues) e, mais especificamente, da subparte referente ao português brasileiro que contém mais de 650 milhões de palavras, contabilizadas em diferentes websites (em torno de 60 mil). A análise tem caráter qualitativo, na medida em que objetiva descrever a convencionalização da unidade linguística sob investigação, a partir de eventos de uso. A hipótese é que o conectivo causal "resultado" perfila a relação causal entre P1 e P2, ao mesmo tempo em que se refere implicitamente ao Ground.

\section{Análise do conectivo "resultado"}

A análise dos dados evidenciou que o conectivo "resultado", tal como outros conectivos causais, introduz e perfila uma relação em que a proposição P2 é subsequente à proposição P1, identificada com a proposição expressa no evento de uso prévio, ocorrido anteriormente no fluxo discursivo.

Além disso, o item "resultado" refere-se implicitamente ao Ground, na medida em que sinaliza a perspectiva do falante em relação à P2. Nesta seção, os fatores que caracterizam essa perspectiva serão detalhados, a partir da noção de que o evento retratado em P2 é uma consequência surpreendente em relação ao evento em P1. Além disso, o evento em P2 pode ser concebido como surpreendente por ser “indesejável” e/ou por ser "contrário às expectativas" sob o ponto de vista do falante. A seguir, essas duas possibilidades serão analisadas.

\section{Indesejabilidade}

O uso do conectivo causal "resultado" para sinalizar uma consequência indesejável corresponde à grande maioria dos casos analisados. Observemos o exemplo a seguir, retirado de uma reportagem que relata os problemas de uma participante de um programa de TV: 
(5) A ex-panicat revela ter sido humilhada e xingada de gorda ao longo dos cinco anos em que trabalhou no extinto programa. Resultado: contraiu depressão, desenvolveu sindrome de pânico, e ainda luta contra a doença. <https://noticiasdatv.uol.com.br/noticia/celebridades/expanicat-relata-humilhacoes-na-tv-e-luta-contra-depressao-tomo-remedio-ate-hoje--22942?cpid=txt>

O exemplo (5) envolve uma relação causal entre "ser humilhada e xingada" e a consequência de "contrair depressão", entre outras doenças. Por se tratar de uma consequência indesejável, o uso do conectivo "resultado" se impõe.

O exemplo a seguir foi retirado de um site de orientação sobre situações da vida prática. Para recomendar uma determinada solução, o texto simula uma situação, em que o ponto de TV por assinatura não está presente em todos os cômodos da casa:

(6) Você está assistindo um seriado na sala e o jantar fica pronto, mas não tem ponto de TV por assinatura na cozinha. Resultado: você vê novela e fica sem saber quem era o assassino.

$<$ http://2centavos.com.br/replicando-a-imagem-de-uma-tv-da-casa-em-outra-sem-fios/>

No exemplo (6), o deslocamento de um indivíduo de um cômodo para outro é apresentado como tendo a consequência de "ficar sem saber quem era o assassino", depois de ter assistido à novela. De forma análoga ao exemplo (5), como a consequência é indesejável, o contexto favorece o uso de "resultado".

Os usos ilustrados nos exemplos (5) e (6) podem ser representados da seguinte forma:

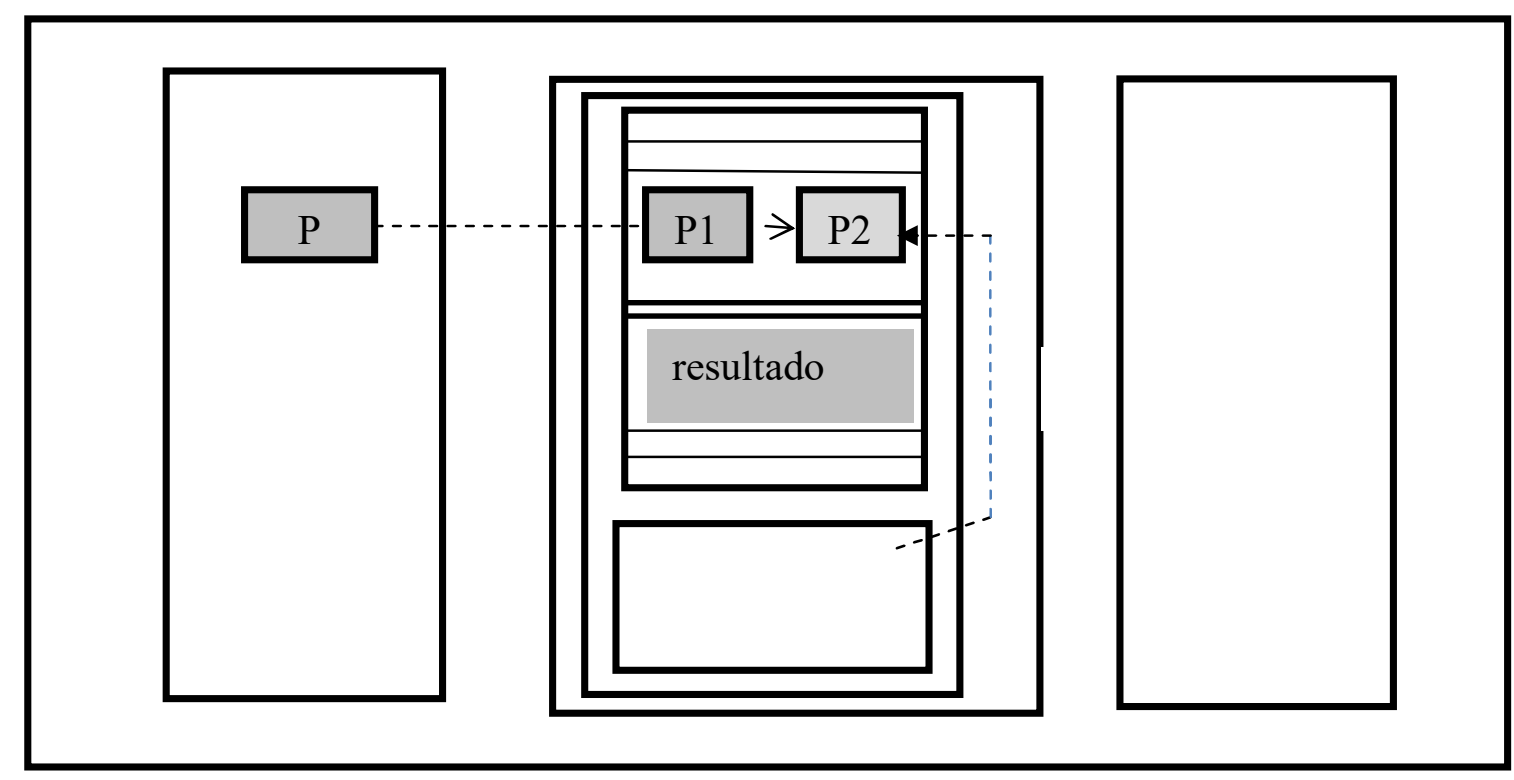

Figura 4 - O conectivo causal "resultado" com P2 indesejável 


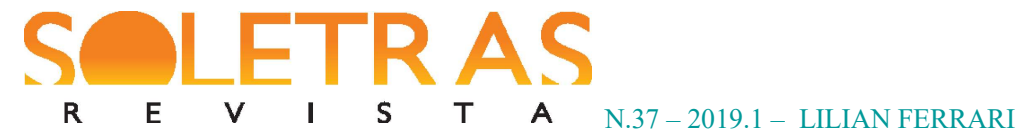

A Figura 4 destaca as informações que coalescem no conectivo causal "resultado", incluindo tanto os elementos colocados em proeminência - a relação causal entre P1 e P2 -, quanto a referência implícita ao Ground, indicando a perspectiva do falante de que P2 é indesejável.

\section{Eventos contrários às expectativas}

Embora os dados evidenciem que o uso de "resultado" está associado, principalmente, a consequências indesejáveis, há também usos em que a consequência não é necessariamente indesejável, mas contraria as expectativas em relação a um determinado evento. Observemos o seguinte trecho, retirado de um artigo sobre economia, que comenta um fato surpreendente relativo aos setores que mais crescem no Brasil:

(7) Curiosamente, os setores que mais crescem no Brasil, o crédito e a construção civil, são os dois mais atingidos nos EUA. (...) A economia americana e a brasileira passam por momentos bastante distintos. Nos Estados Unidos, o setor financeiro e o imobiliário têm, há tempos, uma relação intima. (...) No Brasil, em contraste, até pouco tempo atrás o setor financeiro queria distância do mercado imobiliário. (...) Só com a mudança do marco legal, que deixou o financiamento de imóveis mais parecido com o de automóveis, é que os bancos voltaram a emprestar para o setor. Resultado: esse segmento cresce como nunca, graças à disponibilidade de crédito.

O que se observa no trecho destacado é que a mudança na relação entre o setor financeiro e o mercado imobiliário no Brasil é retratada como causa de um crescimento pouco usual até então. Assim, a consequência (“crescer como nunca”), embora desejável, é surpreendente e contraria expectativas anteriores.

O diagrama a seguir, busca representar os componentes do evento de uso envolvidos nesse caso: 

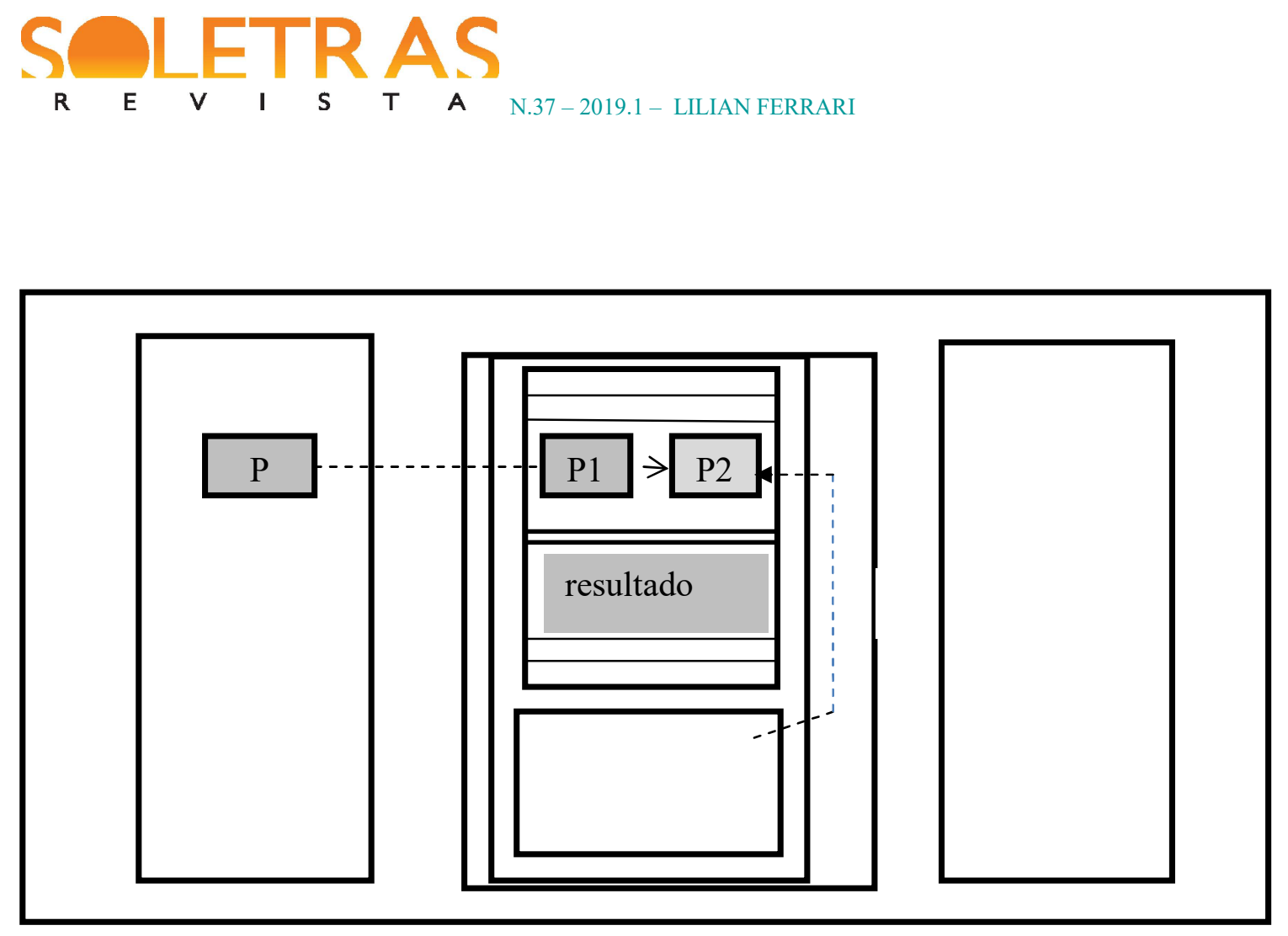

Figura 5 - O conectivo causal "resultado" com P2 contrário às expectativas

A Figura 5 destaca as informações que coalescem no conectivo causal "resultado", incluindo tanto os elementos colocados em proeminência - a relação causal entre P1 e P2 -, quanto a referência implícita ao Ground, indicando a perspectiva do falante de que P2 é surpreendente por ser contrário às expectativas.

\section{Considerações finais}

Este trabalho enfocou as relações entre unidades linguísticas e eventos de uso. A análise alinhou-se ao pressuposto da Gramática Cognitiva de que as expressões linguísticas são produzidas e compreendidas em relação ao contexto discursivo corrente, que molda e sustenta a interpretação.

Assim, partindo da premissa de que aplicações contextuais particulares de unidades linguísticas se tornam consolidadas e convencionalizadas, refletindo a organização conceptual intrínseca de eventos de uso, o trabalho investigou o conectivo causal "resultado". A análise evidenciou que o conectivo perfila uma relação causal entre duas proposições - P1 e P2 -, ao mesmo tempo em que sinaliza a perspectiva implícita do falante em relação à P2. A 


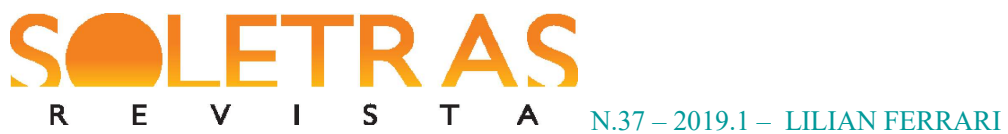

esquematização que se reflete no referido conectivo envolve a avaliação de que a consequência expressa em P2 é surpreendente, tanto por ser avaliada como indesejável, e/ou por ser concebida como contrária às expectativas.

A análise aqui desenvolvida teve por objetivo evidenciar o caráter fundador do modelo langackeriano para o tratamento do significado em suas inter-relações com eventos de uso, bem como integrar novos elementos ao modelo, a partir de estudos sobre conectivos causais sob a ótica dos espaços mentais. A conjugação dessas perspectivas abre novas perspectivas de análise não apenas para outros conectivos causais, mas também para outras unidades linguísticas que sinalizem, implícita ou explicitamente, a perspectiva do falante ou outros elementos do evento de fala.

\section{Referências}

BARLOW, M. \& KEMMER, S. (Eds.). Usage-based models of language. Stanford: CSLI Publications, 2000.

BYBEE, J. Mechanisms of Change in Grammaticization: The Role of Frequency. In B. Joseph \& R. Janda (Eds.), The Handbook of Historical Linguistics. Oxford: Blackwell, 2003a, p. $602-623$.

. Cognitive processes in grammaticalization. M. Tomasello (Ed.), The new psychology of language, v. II. Mahwah, NJ: Lawrence Erlbaum, 2003b.

Language, usage and cognition. Cambridge: Cambridge University Press, 2010.

DIESSEL, H. Usage-Based Construction Grammar. In: DABROWSKA, E.; DIVJAK, D. (Eds.). Handbook of Cognitive Linguistics. Berlin, New York: Mouton de Gruyter, 2015.

DUBOIS, J. Competing Motivations. In J. Haiman (Ed.), Iconicity in Syntax; Typological Studies in Language, vol. 6. Amsterdam: Benjamins, 1985, p. 343-365.

FAUCONNIER, G. Mental spaces. Cambridge: Cambridge University Press, 1994. . Mappings in thought and language. Cambridge: Cambridge University Press, 1997.

; TURNER, M. Conceptual blending and the mind's hidden complexities. New York: Basic Books, 2002.

FERRARI, L.; ANDRADE, H. Subjetividade e conectivos causais no português brasileiro, Linguística (Revista da Alfal), v. 31-1, 2015. p. 111-125. 


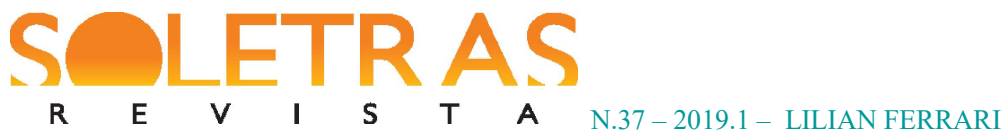

; SWEETSER, E. Subjectivity and upwards projection in mental space structure. In DANCYGIER, B. \& SWEETSER, E. (org.), Viewpoint in language; a multimodal perspective. Cambridge: Cambridge University Press, 2012.

GIVÓN, T. On understanding grammar. New York, Academic Press, 1979.

GEERAERTS, D. Introduction; a rough guide to Cognitive Linguistics. In Geeraerts (ed.). Cognitive Linguistics: Basic Readings. Berlin: Mouton de Gruyter, 2006, p. 1-28.

GOLDBERG, A. Constructions; a construction grammar approach to argument structure. Chicago: The University of Chicago Press, 1995.

HOPPER, P. Emergent grammar. Berkeley Linguistic Society, 13, 1987, p.139-157. 251-299.

\& THOMPSON, S. Transitivity in Grammar and Discourse. Language, 56, 1980, p.

\& TRAUGOTT, E. Grammaticalization (Cambridge Textbooks in Linguistics.) Cambridge: Cambridge University Press, 2003[1993].

LABOV, W. Sociolinguistic Patterns. Philadelphia: University of Pennsylvania Press, 1972.

LANGACKER, R. Foundations of cognitive grammar; theoretical prerequisites. v. 1. Standford CA: Stanford University Press, 1987.

Foundations of cognitive grammar; descriptive applications. v. 2. Standford, CA: Stanford University Press, 1991.

Discourse in Cognitive Grammar. Cognitive Linguistics, v. 12-2, 2001. p. 143-188.

MODER, C. Think of it as: space builders and grounding in public science discourse. In BORKENT, M.; DANCYGIER, B. \& HINNELL, J. (eds.). Language and the creative mind, 2013. p. 203-218.

OAKLEY, T. \& HOUGAARD (eds.), Mental spaces in discourse and interaction. Amsterdam: John Benjamins, 2008. p. 27-50.

SANDERS, T.; SANDERS, J.; SWEETSER, E. Causality, cognition and communication: a mental space analysis of subjectivity in causal connectives. In SANDERS, T.; SWEETSER, E. (eds.). Causal categories in discourse and cognition. Berlin, New York: Mouton de Gruyter, 2009. p. 19-59.

\& SPOOREN, W. Discourse and text structure. In GEERAERTS, D \& CUYCKENS, H. The Oxford Handbook of Cognitive Linguistics. Oxford: Oxford University Press, 2007. p. 916-941. 


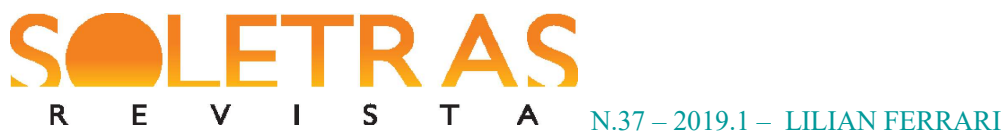

SANKOFF, G. \& BROWN, P. The Origins of Syntax in Discourse: A Case Study of Tok Pisin Relatives. Language, n.3, 1976, p. 631-666.

\title{
Cognitive Grammar and usage events: the causal connective "resultado"
}

\begin{abstract}
This work relies on Cognitive Grammar (LANGACKER, 1987, 1991, 2001), and aims at describing the ways by which linguistic units are abstracted from usage events characterized as real instances of linguistic usage. Drawing on written data available at Corpus do Português (http://www.corpusdoportugues.org), the analysis focuses on the Brazilian Portuguese causal connective "resultado" (roughly, as a result), arguing that its meaning results from the schematization of the relation between propositions P1 (cause) and P2 (consequence), and the speaker's implicit perspective regarding the event described in P2. More specifically, the connective indicates that, from the speaker's perspective, $\mathrm{P} 2$ is undesirable and/or contrary to expectations.
\end{abstract}

Keywords: Cognitive Grammar, linguistic unit, usage event, causal connective.

Recebido em: 20 de novembro de 2018.

Aceito em: 26 de março de 2019. 